\title{
Alois Riegl e "O culto moderno dos monumentos"
}

Claudia dos Reis e Cunha*

\section{Resumo}

Este artigo estuda a obra "O culto moderno dos monumentos", escrita em 1903 pelo historiador da arte vienense Alois Riegl, como parte dos trabalhos de reorganização da legislação de conservação dos monumentos austríacos de que fora encarregado, na qual estabelece princípios para a preservação histórica com base nos "valores" dos monumentos (valor de antiguidade, valor histórico, valor de rememoração intencional, valor de uso, valor de arte relativo e valor de novidade).

Palavras-chave: Alois Riegl. O culto moderno dos monumentos. Tutela e conservação de monumentos históricos.

\section{Alois Riegl and "The modern cult of monuments"}

\section{Abstract}

This article studies the work "The modern cult of monuments", wrote in 1903 by the austrian art historian Alois Riegl, as part as the reorganization of monuments conservation's laws in Austria, in which establishes principles for historic preservation on the basis of the monument's "values" (age-value, historical value, intentional commemorative value, use-value, art-value, newness-value).

Keywords: Alois Riegl. The modern cult of monuments. Protection and conservation of historic monuments

"Der moderne Denkmalkultus" (1) é uma obra de fundamental importância acerca das questões relativas à tutela e conservação dos monumentos históricos. Foi escrita, em 1903, pelo historiador da arte vienense Alois Riegl, designado em 1902, presidente da Comissão de Monumentos Históricos da Áustria, e por ela encarregado de empreender a reorganização da legislação de conservação dos 
monumentos austríacos. "O Culto Moderno dos Monumentos" foi a base teórica para tal empreitada; desse modo, a obra caracteriza-se como "um conjunto de reflexões destinadas a fundar uma prática, a motivar as tomadas de decisão, a sustentar uma política" (WIECZOREK, 1984, p.23).

Riegl organiza a obra em três capítulos, sendo o primeiro dedicado à apresentação dos valores atribuídos aos monumentos e sua evolução histórica; o segundo capítulo trata dos valores de rememoração e sua relação com o culto dos monumentos e, finalmente, o último capítulo aborda os valores de contemporaneidade e sua relação com o culto dos monumentos. Dessa forma, fica claro que o autor empreende uma reflexão que se funda muito mais no valor outorgado ao monumento do que no monumento em si, tratando valor não como categoria eterna, mas como evento histórico (ZERNER, 1995b, p.434).

Ao examinar, no primeiro capítulo, os vários tipos de valor atribuídos aos monumentos, o autor primeiramente define o que seja monumento, diferenciando os monumentos intencionais daqueles não-intencionais. Para Riegl, "no senso mais antigo e verdadeiramente original do termo", (1984, p.35) monumento é uma obra criada pela mão do homem com o intuito preciso de conservar para sempre presente e viva na consciência das gerações futuras a lembrança de uma ação ou destino. Nesse sentido, o monumento, em seu sentido original, relaciona-se com a manutenção da memória coletiva de um povo, sociedade ou grupo. Como ressalta Françoise Choay:

A natureza afetiva do seu propósito é essencial: não se trata de apresentar, de dar uma informação neutra, mas de tocar, pela emoção, uma memória viva. [...] A especificidade do monumento deve-se precisamente ao seu modo de atuação sobre a memória. Não apenas ele a trabalha e a mobiliza pela mediação da afetividade, de forma que lembre o passado fazendo-o vibrar como se fosse presente. Mas esse passado invocado, convocado, de certa forma encantado, não é um passado qualquer: ele é localizado e selecionado para fins vitais, na medida em que pode, de forma direta, contribuir para manter e preservar a identidade de uma comunidade étnica ou religiosa, nacional, tribal ou familiar. (2001, p.18)

A criação desses monumentos intencionais remonta às épocas mais recuadas da cultura humana e, embora ainda hoje, segundo Riegl, não se tenha cessado de 
produzi-los, não é a este tipo de monumento que a sociedade moderna se refere quando se utiliza do termo, mas aos monumentos artísticos e históricos, ou seja, trata-se daqueles monumentos não-intencionais, aos quais "Não é sua destinação original que confere à essas obras a significação de monumentos; somos nós, sujeitos modernos, que à atribuímos". (1984, p.43)

O monumento histórico é para o Alois Riegl uma criação da sociedade moderna, um evento histórico localizado no tempo e no espaço. Após um período em que não se conhecia senão os monumentos intencionais, a partir do século $\mathrm{XV}$, na Itália, as obras da Antiguidade começam a ser valoradas por suas características artísticas e históricas, não mais apenas por serem símbolos ou memoriais das grandezas de Grécia e Roma. Assim, é a partir dessa mudança de atitude que se verifica o despontar de um novo valor de rememoração (RIEGL, 1984, p.49), não mais aquele ligado à memória coletiva, mas ao valor histórico-artístico.

O valor histórico, para Riegl, está diretamente relacionado com a própria noção de história do autor, que chama histórico

[...] tudo aquilo que foi, e não é mais hoje em dia. No momento atual, nós acrescentamos ainda a esse termo a idéia de que aquilo que foi não poderá jamais se reproduzir, e que tudo aquilo que foi constitui um elo insubstituível e intransferível de uma cadeia de desenvolvimento. (1984, p.37)

Afirma ainda que "A noção de desenvolvimento é precisamente o centro de toda concepção moderna de história" (1984, p.37). Essa noção de desenvolvimento ou evolução (2) é fundamental no pensamento riegliano, caracterizando sua abordagem em relação às artes de diferentes períodos e, conseqüentemente, estendida aos monumentos. Para o historiador, a idéia de evolução, surgida na metade do século XIX, confere direito de existência histórica a toda e qualquer corrente artística, inclusive às não-clássicas (RIEGL, 1995, p.143), rompendo dessa forma, com as concepções dogmáticas que apresentavam a sucessão dos estilos artísticos como uma alternância entre florescências e decadências.

Nesse sentido, deve-se sublinhar que não existe para Riegl um valor artístico absoluto, mas apenas um valor relativo, desde que, no início do século XX, a crença 
na inexistência de um cânone artístico ou de um ideal artístico objetivo e absoluto paulatinamente se impôs à antiga tese de que havia um tal cânone. Em decorrência, não se pode falar, dentro do contexto do Denkmalkultus, em monumentos artísticos, mas apenas históricos, pois seu valor não é um valor para a arte, e sim para a história da arte.

Em conseqüência, a definição do conceito de "valor de arte" deverá variar segundo o ponto de vista que cada um adote. Segundo a concepção antiga, uma obra de arte possuía um valor artístico na medida em que ele respondesse às exigências de uma estética supostamente objetiva, mas não sucedeu nesses dias dar lugar a alguma formulação incontestável. Segundo a concepção moderna, o valor de arte de um monumento se mede pela maneira com que ele satisfaça às exigências da vontade artística moderna. (RIEGL, 1984, p.41)

Ou seja, o valor que é atribuído ao monumento, e daí a forma específica que este culto irá assumir, está diretamente relacionado com outro conceito-chave do pensamento de Riegl, a kunstwollen - vontade artística - de cada época. Se até o século XVIII as preceptivas dominaram o fazer artístico, os monumentos tinham, necessariamente, que responder a esse cânone para serem admitidos como tal. A partir do século XIX, porém, quando passa-se a negar a validade dessas preceptivas, abre-se caminho para a valoração positiva de toda e qualquer manifestação artística e, dessa forma, amplia-se sobremaneira o alcance do culto patrimonial, resultando, bem assim, em formas distintas de intervenção e tutela desses monumentos.

Ainda a respeito da visão historiográfica de Alois Riegl, cabe destacar a importância do empirismo em suas pesquisas, manifesta não apenas no Denkmalkultus, mas, entre outros, em seu Stilfragen, de 1893, ou ainda em Spätromische Kunstindustrie, de 1901, nas quais as obras de arte são consideradas documentos históricos e, portanto, passíveis de serem analisadas de maneira análoga (WIECZOREK, 1984, p.23) (3). Segundo Willibald Sauerländer, "Empirismo e teoria, descrição estreitamente inerente aos fatos e especulação construtiva são nos escritos de Riegl unidos" (1995, p.426) 
Em seu segundo capítulo, Denkmalkultus trata especificamente dos valores de rememoração, que se dividem em valor de antiguidade, valor histórico e valor de rememoração intencional, sendo que

A classe dos monumentos intencionais diz respeito às obras destinadas, pela vontade de seus criadores, a comemorar um momento preciso ou um evento complexo do passado. $\mathrm{Na}$ classe dos monumentos históricos, o círculo se alarga àqueles que apresentam ainda um momento particular, mas cuja escolha é determinada por nossas preferências subjetivas. $\mathrm{Na}$ classe dos monumentos antigos entram enfim todas as criações do homem, independentemente de sua significação ou de sua destinação original [...] As três classes aparecem assim como três estados sucessivos de um processo de generalização crescente do conceito de monumento. (RIEGL, 1984, p.47)

O valor de antiguidade para Riegl revela-se imediatamente, ao primeiro contato, com uma obra na qual fica claro seu aspecto não-moderno, isto é, tal valor surge do contraste, da diferença, que pode ser percebida não apenas pelas classes mais instruídas ou cultivadas, mas inclusive pelas massas. E é esse apelo às massas, presente no valor de antiguidade, que fez com que o historiador acreditasse em sua ascendência no nascente século $X X$, onde passava a predominar uma cultura de massas.

O valor de ancianidade do monumento histórico não é para ele uma promessa, mas uma realidade. A imediatez com a qual esse valor se apresenta a todos, a facilidade com que se oferece à apropriação das massas (Massen), a sedução fácil que ela exerce sobre estas deixam entrever que ele será o valor preponderante do monumento histórico no século XX. (CHOAY, 2001, p.169)

A eficácia estética do valor de antiguidade reside exatamente em seu aspecto vetusto, nos traços de decomposição impostos à obra pelas forças da natureza, alterando sua forma e cor, fazendo aflorar no espectador a sensação do tempo transcorrido, do ciclo de criação-destruição, que se apresenta como lei inexorável da existência. Por isso, o valor de antiguidade determina como pressuposto de ação conservativa exatamente a não-intervenção, ou seja, "ao menos em princípio, ele rejeita toda ação conservativa, toda restauração, enquanto intervenção injustificada sobre o desenrolar das leis da natureza" (RIEGL, 1984, p.69). Entretanto, essa posição não-interventora em relação aos monumentos não significa a aceitação de 
uma destruição violenta, seja em decorrência da ação do homem, seja proveniente das forças naturais.

Por sua descrição, o valor de antiguidade, à primeira vista, se assemelha àquela sensibilidade dos românticos, entretanto, ainda que aparentemente próximos, Riegl diferencia claramente o gosto moderno pelo monumento antigo do apreço barroco pelas ruínas. Segundo ele, não há nada mais estranho à sensibilidade moderna que o gosto romântico, para o qual,

A ruína deveria simplesmente levar à consciência do espectador o contraste, essencialmente barroco, entre a grandeza do passado e a decadência presente. Ela exprime o pesar dessa queda, e a nostalgia correlativa de uma antiguidade que desejariam ver conservada: trata-se, por assim dizer, de um deleite voluptuoso na dor, que, mesmo atenuado por uma certa inocência pastoral, faz o valor estético do pathos barroco. (RIEGL, 1984, p.62)

Ao contrário, a apreciação moderna vê nas ruínas a manifestação do ciclo natural a que se submete inelutavelmente toda obra humana, aqui entendida como um organismo natural, o qual deve se desenvolver livremente, protegido apenas de um fim prematuro. O autor mostra que, analogamente ao desenvolvimento do valor da antiguidade, a proteção de animais, plantas ou ainda florestas inteiras, denominados a partir de então como monumentos naturais, desponta como outro traço característico da cultura moderna. (RIEGL, 1984, p.67)

O momento em que Denkmalkultus está sendo escrito por Alois Riegl, início do século XX, marca para o historiador a passagem do valor histórico - predominante até o XIX - ao de antiguidade. Segundo ele, em tempos de mudanças profundas na sociedade, como a que presenciava no fin-de-siécle, valores novos e antigos conviviam, até que os primeiros se impusessem definitivamente sobre os últimos.

Assim, parece que o valor de rememoração, que se constitui num dos fatores dominantes da cultura atual, ainda não está de modo nenhum chegado, sob sua forma absoluta de valor de antiguidade, a uma maturidade que nos permita passar totalmente de sua forma histórica. (RIEGL, 1984, p.78)

O prazer estético proveniente da contemplação de um monumento não se esgota na constatação de sua vetustez, de seu aspecto antigo, mas se completa com o 
conhecimento, ainda que superficial, do estilo empregado, da época em que foi construído, o que implica um conhecimento de história da arte e, portanto, o prazer proveniente desse conhecimento não é um prazer imediato, ao contrário, é reflexivo e científico (RIEGL, 1984, p.77), extrapola o valor de antiguidade e caracteriza o valor histórico. Ademais, o valor histórico vem do reconhecimento de que um determinado monumento representa um estado particular e único no desenvolvimento de um domínio da criação humana (RIEGL, 1984, p.73), ou seja, o monumento passa a ser identificado como documento histórico e, por essa razão, deve ser mantido o mais fiel possível ao estado original, como no momento preciso de sua criação, implicação direta no método de conservação adotado, que deve, por oposição ao postulado pelo valor de antiguidade, buscar a paralisação do processo de degradação sofrido pela obra, ainda que admita as transformações já impostas pelo tempo como parte da história do próprio monumento.

O último dos valores de rememoração, o valor de rememoração intencional é, para Riegl, o que mais se aproxima dos valores de contemporaneidade, na medida em que remete-se à busca de um eterno presente e exige do monumento "nada menos [...] que a imortalidade, o eterno presente, a perenidade do estado original" (1984, p.85). A diferença que se coloca entre valor de rememoração, seja de antiguidade ou intencional, e os valores de contemporaneidade, reside em que

No lugar de considerar o monumento enquanto tal, o valor de contemporaneidade tenderá de imediato a nos fazer tê-lo como igual a uma criação moderna recente, e exigir portanto que o monumento (antigo) apresente um aspecto característico de toda obra humana em sua primeira aparição: dito de outro modo, que dê a impressão de uma perfeita integridade, não tocado pela ação destrutiva da natureza. (RIEGL,1984, p.87)

Os valores de contemporaneidade, apresentados por Alois Riegl no último capítulo de Denkmalkultus, dividem-se em dois tipos: valor de uso prático, ou apenas valor de uso, e valor de arte, sendo que este divide-se em valor de arte relativo e valor de novidade. No caso do valor de uso, o monumento deve atender às necessidades materiais do homem, enquanto o valor de arte atende às necessidades do espírito, segundo caracterização dada pelo autor.

Ao lado do transcendente "valor artístico", Riegl coloca, com efeito, um valor terreno "de uso", relativo às condições materiais de utilização prática dos monumentos. Consubstancial ao monumento sem qualificação, segundo Riegl, esse valor de uso é igualmente inerente a 
todos os monumentos históricos, quer tenham conservado seu papel memorial original e suas funções antigas, quer tenham recebido novos usos, mesmo museográficos. (CHOAY, 2001, p.169)

O valor de arte relativo refere-se à capacidade que o monumento antigo mantém de sensibilizar o homem moderno, ou seja, ainda que tenham sido criados movidos por uma kunstwollen radicalmente diferente da nossa, alguma característica de concepção, forma ou cor específica do monumento, a despeito de sua aparência não-moderna, torna-o capaz de satisfazer a kunstwollen moderna. De outro modo, principalmente entre as camadas menos cultivadas da população, quando se espera do monumento a aparência nova e fresca de uma obra recém-criada, o valor de arte predominante é o valor de novidade.

O caráter acabado do novo, que se exprime da maneira mais simples por uma forma que ainda conserva sua integridade e sua policromia intacta, pode ser apreciada por todo indivíduo, mesmo completamente desprovido de cultura. É por isso que o valor de novidade sempre será o valor artístico do público pouco cultivado. (RIEGL, 1984, p.96)

Segundo Riegl, o valor de novidade atende àquela atitude milenar que atribui ao novo uma incontestável superioridade sobre o velho, tal atitude "está tão solidamente ancorada [na sociedade] que não poderá ser extirpada no espaço de alguns decênios" (1984, p.96), e de fato, até nossos dias ainda permanece.

Um século após a publicação de Der moderne Denkmalkultus, verifica-se que o valor de antiguidade não conseguiu, como acreditava Riegl, se impor sobre o valor de novidade, mesmo entre aqueles mais cultivados e não somente entre as massas. $O$ gosto crescente pelos monumentos do passado, fator incontestável em nossa sociedade - a ponto de se falar em uma inflação patrimonial -, (CHOAY, 2001, p.240 et seq.) não se dá em função de seu aspecto de vetustez, que continua a não corresponder a nossa kunstwollen contemporânea. Mesmo aos monumentos antigos impõe-se que se apresentem como novos, com seu aspecto acabado e fresco, tal como uma obra recente. Assim, o patrimônio histórico na sociedade contemporânea, mais do que perpetuar uma memória, presta-se a reafirmar o desejo humano de imortalidade, de perenidade, em sua constante luta contra a dissolução e a morte. 
A grande contribuição dessa obra do historiador da arte vienense reside no fato de se apresentarem, através dos diferentes tipos de valor atribuídos aos monumentos, decorrentes das distintas formas de percepção e recepção dos monumentos históricos em cada momento e contexto específicos, os contrastantes meios para sua preservação. E, ao indicar essas múltiplas possibilidades, impor ao sujeito da preservação a necessidade de fazer escolhas, as quais devem ser, necessariamente, baseadas num juízo crítico. Dessa forma, o pensamento riegliano insere definitivamente as práticas da restauração no debate sobre a cultura, considerando-a deliberadamente como "ato de cultura", antecipando-se às propostas defendidas a partir do segundo pós-guerra europeu pelo chamado "restauro crítico", que tem nas figuras de Roberto Pane, Renato Bonelli e Agnoldomenico Pica seus protagonistas, e, paralelamente, a marca da contribuição teórica de Cesare Brandi.

Ao concluir observamos como Riegl conjuga um trabalho de radical repensamento e, podese dizer, de fundação conceitual, único e para muitos ainda hoje insuperado; mas nenhum antes dele se deteve com tanta perspicácia sobre a análise das razões mesma do conservar, procedendo sempre com rigor dentro do campo estritamente disciplinar, sem desvios nem quedas no senso sociológico e moralista de um lado, étnico-político e nacionalista de outro. [...] Aquilo que ao contrário se apresenta com um diferente grau de definição, tanto é, em boa medida, demandado da sensibilidade do indivíduo conservador, quanto da proposta operativa, são as conseqüências práticas e aplicativas de uma finíssima premissa; por isso, talvez justamente, cada especificação torna-se inútil quando são garantidas a boa disposição, a preparação, o equilíbrio de juízo, o bom senso do restaurador. E propriamente esse constante, implícito reclamo ao ato de juízo aproxima Riegl, [...] inopinadamente aos sucessivos desenvolvimentos do "restauro crítico" e do pensamento de Cesare Brandi. (CARBONARA, 1997, p.226, tradução nossa)

\section{Notas}

(1) (O culto moderno dos monumentos) Neste trabalho será utilizada a tradução francesa: RIEGL, Aloïs. Le culte moderne des monuments. Son essence et sa genèse. Traduit par Daniel Wieczorek. Paris: Seuil, 1984. Todas as citações aqui apresentadas foram traduzidas do original pela própria autora.

(2) Na tradução francesa do Denkmalkultus Daniel Wieczorek dá preferência ao termo desenvolvimento em vez de evolução para evitar qualquer conotação darwinista, que não é absolutamente própria a Riegl. Ver RIEGL, op. cit., p.121.

(3) Ver também PÄCHT, Otto. Aloïs Riegl. In: RIEGL, Aloïs. Grammaire historique des arts plastiques. Paris: Klincksiek, 1978, p.X. 


\section{Referências Bibliográficas}

BRANDI, Cesare. Teoria da Restauração. Tradução Beatriz Mugayar Kühl. São Paulo: Ateliê Editorial, 2004.

BREITLING, Peter. The origins and development of a conservation philosophy in Austria. In: KAIN, Roger (ed.).

Planning for Conservation. London: Mansell, 1981, p.49-61.

CARBONARA, Giovanni. Avvicinamento al restauro. Teoria, storia, monumenti. Napoli: Liguori, 1997.

CHOAY, Françoise. A Alegoria do Patrimônio. Tradução Luciano Vieira Machado. São Paulo: Estação Liberdade/ Unesp, 2001.

PÄCHT, Otto. Aloïs Riegl. In: RIEGL, Aloïs. Grammaire Historique des Arts Plastiques. Volonté artistique et vision du monde. Paris: Klincksieck, 1978, p.IX - XXVI.

PANOFSKY, Erwin. Alois Riegl y el concepto de Kunstwollen. In: PATETTA, Luciano. Historia de la Arquitectura. Antología critica. Madrid: Celeste, 1997, p.23-25.

RIEGL, Aloïs. Le culte moderne des monuments. Son essence et sa genèse. Tradução Daniel Wieczorek. Paris: Seuil, 1984.

Opera della natura e opera d'arte. In: SCARROCCHIA, Sandro (a cura di). Aloïs Riegl: teoria e prassi della conservazione dei monumenti. Antologia di scritti, discorsi, raporti - 1898-1905. Bologna: Clueb, 1995.

SAUERLÄNDER, Willibald. Riegl e gli inizio del'autonomia della storia dell'arte. In: SCARROCCHIA, Sandro (a cura di). Aloïs Riegl: teoria e prassi della conservazione dei monumenti. Antologia di scritti, discorsi, raporti 1898-1905. Bologna: Clueb, 1995.

SCARROCCHIA, Sandro (a cura di). Aloïs Riegl: teoria e prassi della conservazione dei monumenti. Antologia di scritti, discorsi, raporti - 1898-1905. Bologna: Clueb, 1995.

SWOBODA, K.M. \& PÄCHT, O. Introduction. In: RIEGL, Alöis. Grammaire Historique des Arts Plastiques. Volonté artistique et vision du monde. Paris: Klincksieck, 1978, p. XXVII - XXXIV.

WIECZOREK, Daniel. Introduction du traducteur. In: RIEGL, Aloïs. Le culte moderne des monuments. Son essence et sa genèse. Traduit par Daniel Wieczorek. Paris: Seuil, 1984.

ZERNER, Henri. A arte. In: LE GOFF, Jacques; NORA, Pierre (dir.). História: novas abordagens. Tradução Henrique Mesquita. 4. ed. Rio de Janeiro: Francisco Alves, 1995, p.144-159.

La teoria critica dei valori di Riegl. In: SCARROCCHIA, Sandro (a cura di). Alois Riegl: teoria e prassi della conservazione dei monumenti. Bologna: Clueb, 1995. 
*Arquiteta. Especialista em História e Cultura pela Universidade Metodista de Piracicaba - UNIMEP. Mestre e Doutoranda em História e Fundamentos da Arquitetura e do Urbanismo pela FAU-USP. Editora assistente do Portal Vitruvius.

Este trabalho é baseado em parte do segundo capítulo da dissertação de mestrado "O patrimônio cultural da cidade de Sorocaba: análise de uma trajetória", defendida em 2005 pela autora na FAUUSP, realizada com apoio do Conselho Nacional de Desenvolvimento Científico e Tecnológico CNPq. 